Original Research

\title{
Coral Reef Mapping Using Remote Sensing Techniques and a Supervised Classification Algorithm
}

\author{
Erina White ${ }^{1}$, Farzane Mohseni ${ }^{2}$, Meisam Amani ${ }^{3,}{ }^{*}$
}

1. Ocean Mapping Diploma Program, Fisheries and Marine Institute of Memorial University of Newfoundland, St. John's, NL, Canada, A1C 5R3; E-Mail: erina.white@mi.mun.ca

2. Faculty of Geodesy and Geomatics Engineering, K. N. Toosi University of Technology, Tehran, Iran; E-Mail: farzanemohseni@ymail.com

3. Wood Environment and Infrastructure Solutions, Ottawa, ON, Canada, K2E 7L5; E-Mail: Meisam.amani@woodplc.com

* Correspondence: Meisam Amani; E-Mail: Meisam.amani@woodplc.com

Academic Editor: Giacomo De Carolis

Special Issue: $\underline{\text { Remote Sensing and Oceans }}$

Adv Environ Eng Res

2021, volume 2 , issue 4

doi:10.21926/aeer.2104028
Received: August 28, 2021

Accepted: October 24, 2021

Published: November 04, 2021

\begin{abstract}
The vitality of the Great Barrier Reef (GBR) is threatened by many human-made impacts. Monitoring this ecosystem makes it possible to study the general condition and the health of the GBR. However, due to the large extent of the GBR and limited accessibility in the ocean environment, mapping and monitoring this ecosystem has been always challenging task and connived. In this regard, Remote Sensing (RS) is an effective technique that provides valuable information for mapping and monitoring this ecosystem. In an attempt to monitor the GBR, this article applied a supervised machine learning algorithm to classify the Landsat 8 imagery collected over the GBR. To this end, the spectral responses of coral reefs, shallow water, deep ocean, rocks and sands, and green alga were initially determined from the satellite images. This information was then ingested to the Maximum Likelihood supervised classifier to map coral reefs in the GBR. Additionally, this study discusses how the GBR has been affected by anthropogenic disturbance. The results provide confirmatory evidence that
\end{abstract}

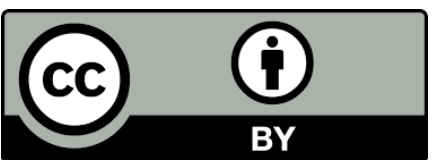

(C) 2021 by the author. This is an open access article distributed under the conditions of the Creative Commons by Attribution License, which permits unrestricted use, distribution, and reproduction in any medium or format, provided the original work is correctly cited. 
RS techniques present great promise as a means of mapping coral reefs and monitoring their general conditions. We used the ambiguity matrix and validation data to estimate the accuracy of the proposed method. Overall, the proposed method was able to identify 5 different classes considered in this article with an average accuracy of $90 \%$.

\section{Keywords}

Great barrier reef; ocean; Landsat 8; maximum likelihood; machine learning classifier

\section{Introduction}

Coral reefs hold an immense importance to the marine ecosystem. They are the habitats for at least $25 \%$ of all marine species [1]. Coral reefs have a numerous benefits to flood and coastline protection [2, 3], tourism [4], fisheries, and human food [5]. Moreover, coral reefs are home for approximately 4,000 species of marine life [6]. However, because of climate change, industrialization, and anthropogenic disturbance, $54 \%$ of the world's coral reefs are extremely susceptible to degradation from regional or global threats. In this regard, the Great Barrier Reef (GBR) in Australia is no exception.

The GBR is the largest coral reef ecosystem in the world that spans over 14 degrees of latitude and extends over 2,300 kilometres along the Northeast coast of Australia. This ecosystem is of great importance due to many reasons, such as protecting more than 275 million people through the absorption of wave energy which reduces damages to coastlines and structures due to storms, hurricanes, or cyclones [7]. Moreover, the GBR has such an extensive diversity of species that no other 'World Heritage Site' on Earth possesses such diversity. This diversity of species includes but is not restricted to, over 410 species of hard coral, over 1,620 species of fish, 2,000 species of sponge, 14 species of sea snake, 6 out of 7 species of marine turtle, at least 300 mollusc species, 630 species of echinoderm, and 500 species of marine alga [8]. However, the vitality of the GBR is threatened by seven key indirect or direct pressures, including climate change, declining water quality, coastal development, shipping impacts, fishing impacts, diseases and pest species, and marine debris [9]. The fundamental resilience of this significant coral reef ecosystem has been gravely compromised and many elements of the biological diversity for which it is recognized for, may be at risk of extinction [8]. Majority of the threats identified to be harming the diversity of marine life on the GBR over the last couple decades continue to be addressed but many of these threats are worsening [8]. The increasing impacts like widespread coral bleaching and other damaging impacts have amplified preservation concerns for the future of the GBR. Intelligent monitoring and mapping the ecosystem of this area allows for researchers to determine the health of the GBR and discover ways on how it can be protected [10]. In this regard, RS present great means of monitoring and mapping this ecosystem thanks to the accessibility of the frequent highresolution satellite images [11]. RS techniques can be effectively employed to determine both anthropogenic and natural effects on coral reefs in the GBR [12]. These methods allow for the instantaneous study of reef areas for the evaluation of spatial patterns and can provide a high frequency of observation for the determination of temporal patterns [13-15]. 
During the past few decades, the observations from various RS satellites have been used to provide key information on coral reef environments, such as the GBR [16, 17]. In this regard, Landsat 8 satellite data can be considered as the main RS instruments applied for data acquisition on coral reefs since the mid 1980's. Landsat 8 has 11 spectral bands; each of them measures different ranges of frequencies along the electromagnetic spectrum. Of its 11 bands, bands 1-4 and 8 sense visible light. Band 1 measures deep blues and violets. Bands 2, 3, and 4 are visible blue, green, and red, respectively. Band 5 covers the NIR spectrum. Bands 6 and 7 cover different parts of the shortwave infrared. All of the mentioned bands have the spatial resolution of $30 \mathrm{~m}$. However, Bands 10 and 11, which are in the thermal infrared portion of the electromagnetic spectrum, have the spatial resolution of $100 \mathrm{~m}$. From all bands of Landsat 8 , band 8 is a panchromatic band and has the spatial resolution of $15 \mathrm{~m}$ [18]. High bandwidth, easy accessibility, appropriate temporal interval, and suitable spatial resolution have made Landsat 8 one of the most widely used Rs systems in ocean studies $[19,20]$. In this study, Landsat images along with a supervised classification algorithm, called Maximum Likelihood were implemented to identify the coral reefs in the GBR of Australia.

\section{Study Area and Data}

\subsection{Study Area}

The study area is the GBR region, located in Coral Sea, Australia (central coordinate: $150.402 \mathrm{~W}$, $21.043 \mathrm{~S}$ ). Due to the large extent of the GBR, which is over 2,300 kilometres in length, only a portion of this region was considered as the study area (see Figure 1). The spatial extent of the satellite imageries that covered large area of the GBR corals and included least amount of cloud coverage was selected as the study area. Therefore, the North-East coast of Australia, towards the lower end of the GBR was selected as the study area.

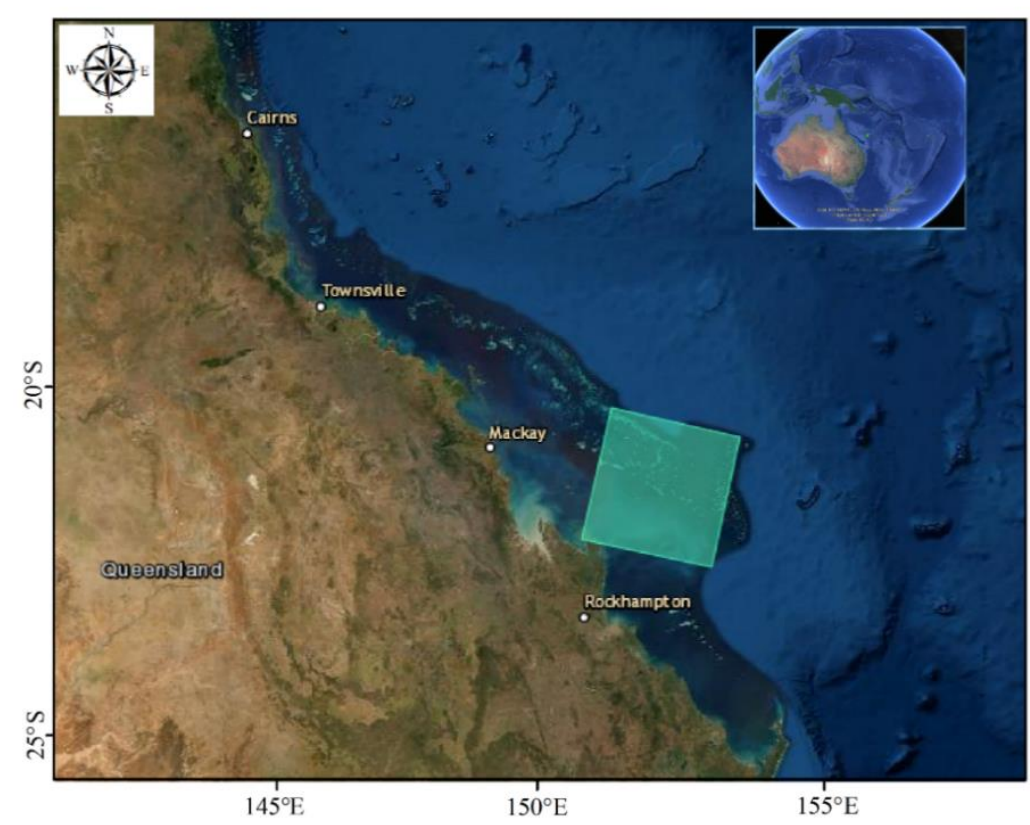

Figure 1 The geographic location of the Great Barrier Reef (GBR) area, located in Coral Sea, along with the spatial extent of the study area (red square). 


\subsection{Datasets}

To provide a medium-resolution classification map of the coral reef in the GBR region, a Landsat 8 image was utilized. As mentioned before, among the 11 spectral bands of Landsat 8, band 1 to 7 have the spatial resolution of $30 \mathrm{~m}$. Therefore, these bands (bands that cover deep blues and violets, blue, green, red, NIR, and tow shortwave infrared) were used for classification. As mentioned before, the study area was limited to one satellite image scene (red boundary in Figure 1). The Landsat 8 image of study area was obtained from the Earth Explorer platform (https://earthexplorer.usgs.gov/), where the United States Geological Survey (USGS) provides satellite imagery across the globe. From all images of Landsat 8, those images with more than 0-6\% cloudy pixels over the study area were initially excluded. Finally, the Landsat 8 image of August 29th of 2018 which provided cloudless imagery was downloaded. Figure 2 shows the true colour composite of the Landsat 8 image which was used in this study. In this study, both shallow water and deep water were considered in the classification. Briefly, the deep open ocean waters in which phytoplankton is the major determinant of water spectral characteristics are referred to as case-1 of water [21]. Case-2 waters, which are more turbid than open ocean, refers to the shallow costal water. The case- 2 of waters are generally shallow so the underwater surface or the particles may be visible. Therefore, the spectral properties of case- 2 waters are affected by different optically active constituents, such as mineral particles, Colored Dissolved Organic Matter (CDOM), and microbubbles [22]. Since the case-2 of water is naturally shallow, the waters around the rocks in the oceans are considered as case- 2 of water. The presence of rocks near the surface of ocean causes that these waters to be considered as the case-2 of water [23]. To better representation of the case- 1 and case- 2 of water existed in the ocean, Figure 2 shows two different band combinations with different visualization parameters. As is clear, the ocean deep water is distinguishable from shallow water. For example, Figure 2 (a) shows some white and shiny rocks that can be divided into two types. The first group of rocks are those that can be seen in a Landsat 8 RGB image. These rocks are out of the water surface and can easily be observed in the RGB image. However, although several racks are not visible in the RGB image, they are discernible in the band combinations images (two zoomed images). They are bottom and near-surface rocks, and the water around them are mostly shallow waters. Moreover, both sallow water and deep water are distinguishable in Figure 2 (b). Shallow water can be found in the upper right corner of Figure 2 (b). The rest of water areas are mostly deep waters. 

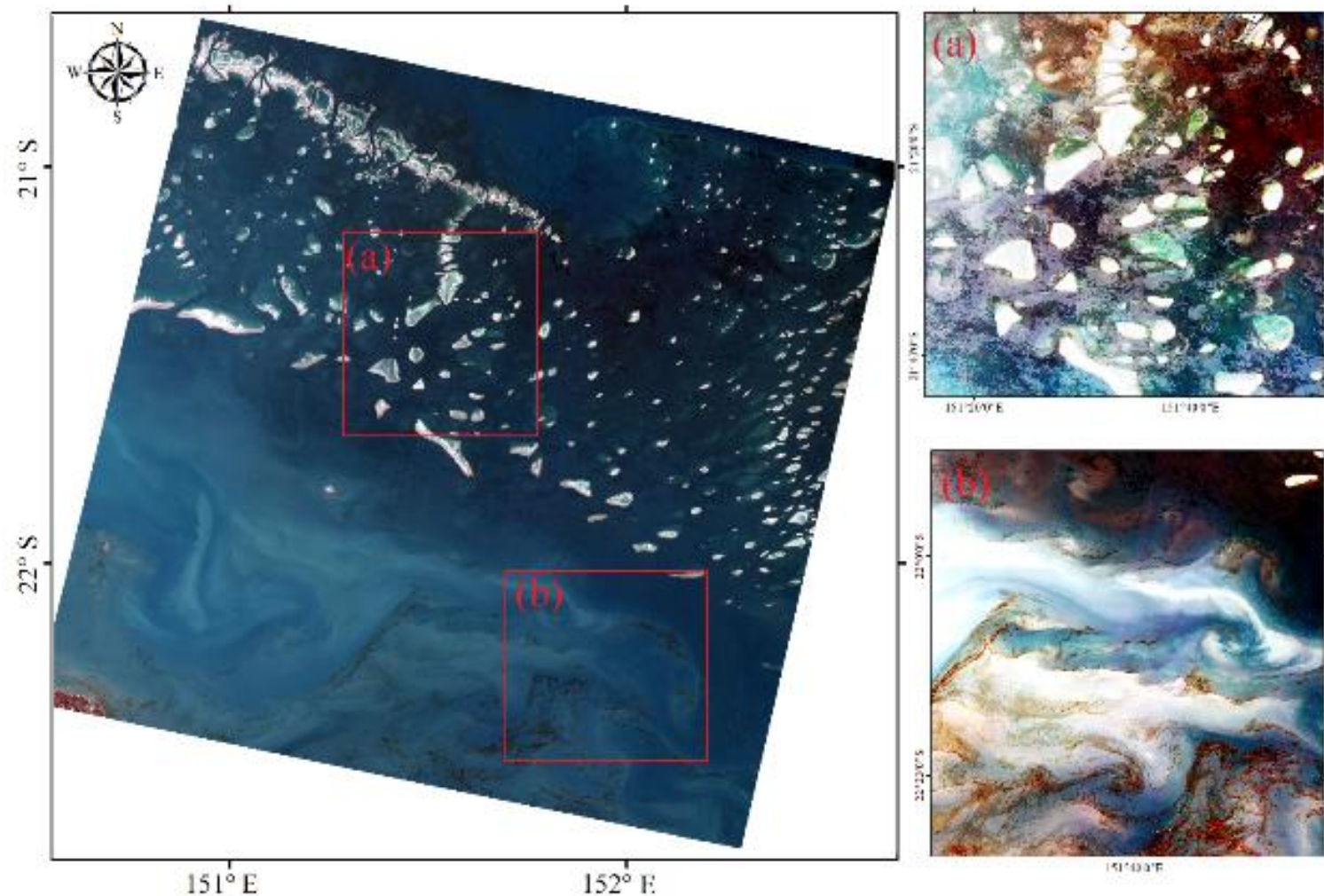

Figure 2 Landsat 8 satellite image over the study area. (a) and (b) show different band combinations of a Landsat 8 image with different visualization parameters to represent different classes (e.g., rock, shallow water, and deep water) in the study area.

\section{Methodology}

The selected Landsat 8 image was imported into the ArcGIS software to perform a supervised classification based on the Maximum Likelihood algorithm. It should be noted that before importing data into the ArcGIS software, we applied the atmospheric and radiometric correction using the ENVI software package. A comprehensive description about the corresponding corrections and their parameters and factors can be found in [24]. Given the characteristics of coral reefs of the selected area in the GBR, this study considers five classes of the ocean water (including shallow water (case-2 of water) and deep water (case-1 of water)), coral reef, rocks and sands, and green alga. Training samples of each corresponding classes were visually selected from the image using the Training Sample Manager (TSM) module of the image classification tool in ArcMap. To have a comprehensive evaluation of the proposed method, both point- and polygonbased training samples were considered in this study. In order to achieve more than $70 \%$ confidence of the supervised classification, at least 10 samples with various geographic locations were considered for each class. Figure 3 presents one training sample area of each of the five classes. All ten training samples of each class were then merged to create the comprehensive training data utilized for the supervised classification. 


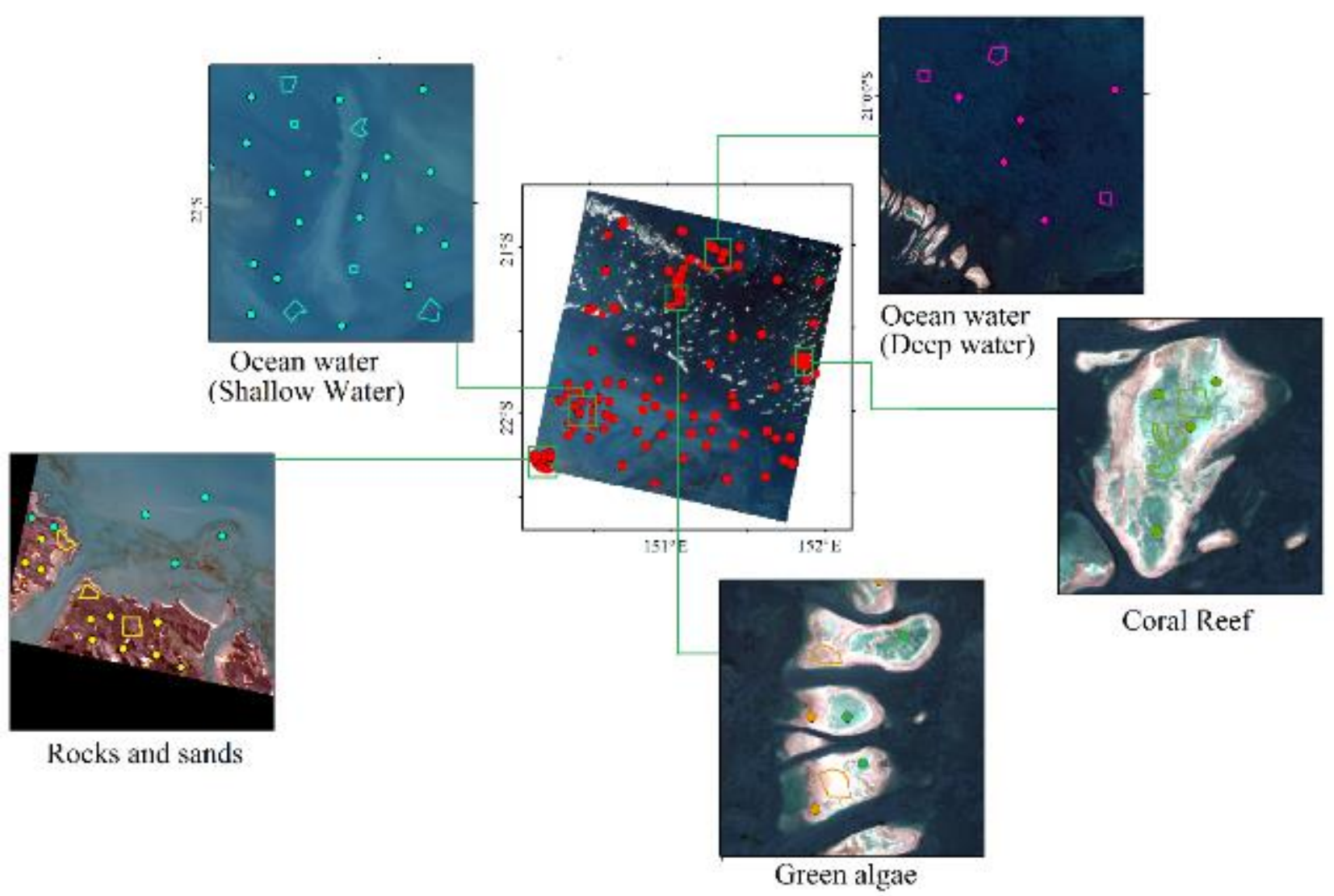

Figure 3 Training samples for different coral reef classes.

\section{Results and Discussion}

The reliability of the training samples is an essential factor to obtain a high classification accuracy using supervised classification algorithms. Therefore, the spectral responses of the generated samples of the five coral reef classes in different bands of Landsat 8 imagery were initially investigated. To this end, a comparison analysis between the histograms of the training samples, as well as between the scatter plots of samples was conducted, where the results are illustrated in Figure 4. Using these results, one can figure out that if the selected training samples can distinguish five different classes of coral reefs. Moreover, it can be identified that which of the Landsat 8 bands is more suitable to identify and detect different coral reef classes. 

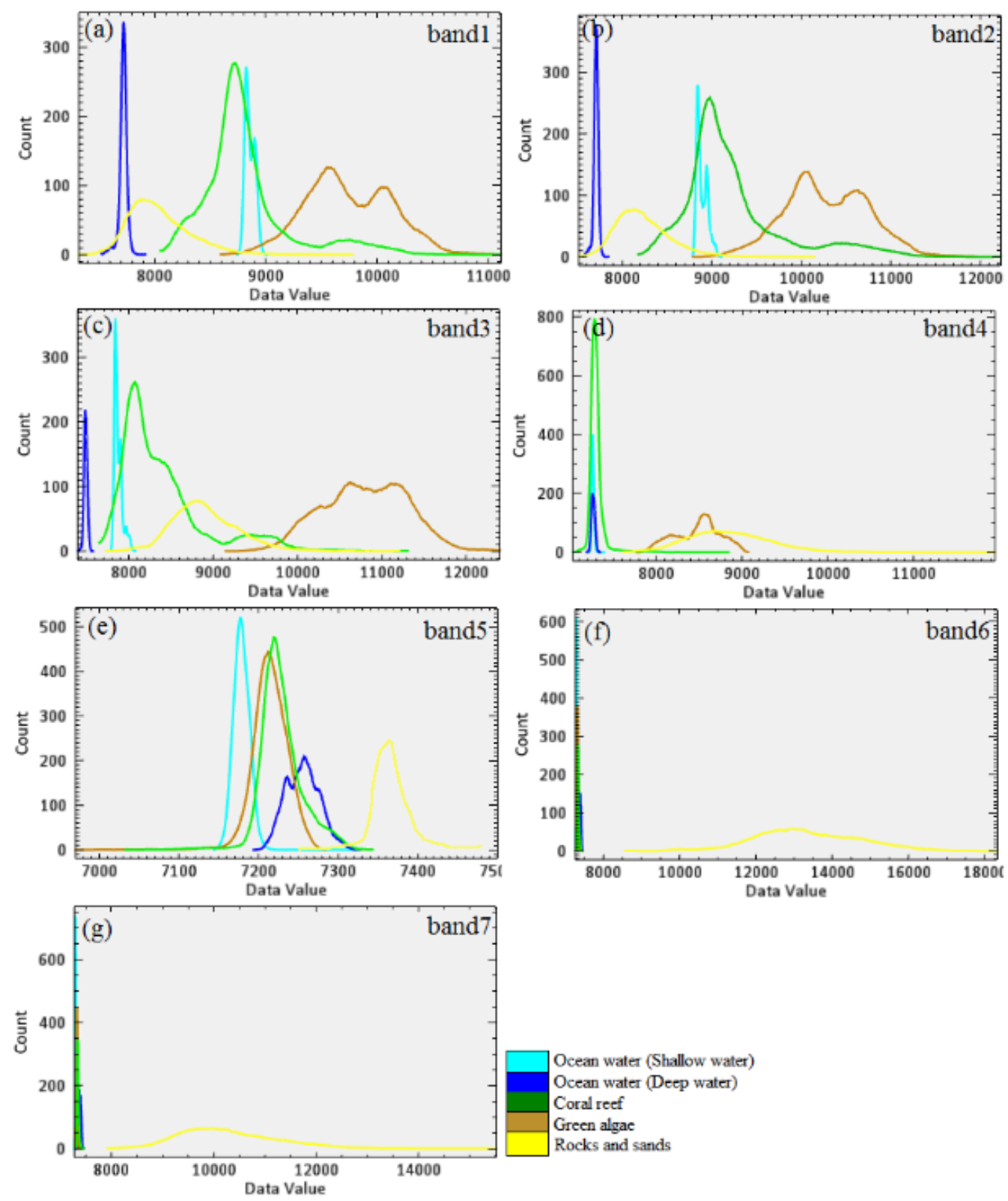

Figure 4 Histograms of the values of the training samples for five coral reef classes using different spectral bands of Landsat 8 imagery.

According to Figure 4, there is no/little overlapping between the histograms of classes in most of the spectral bands of Landsat 8 images, meaning that the training samples are able to distinguish the coral reef classes. Overall, the histogram of band 3 (Figure 4 (c)) had the highest potential to distinguish between different classes. However, the bands 6 and 7 can only distinguish the rocks and sands. It means that these two bands were not appropriate for classification. Moreover, according to Figure 4, there were no large outliers between the histograms of bands 2 and 3 , and none of the histograms had multiple peaks (i.e., multimodal distribution). If any of these two issues were detected in the histograms of the classes, the sample selection step must be repeated for the corresponding classes.

After comprehensive evaluation of the training samples and image bands, the selected Landsat 8 image was classified into different coral reef classes using the Maximum Likelihood supervised 
classification algorithm. The result of the classification for the entire study area is shown in Figure 5. Moreover, Figure 6 presents a visual comparison between the classified map and the satellite image for a zoomed area.

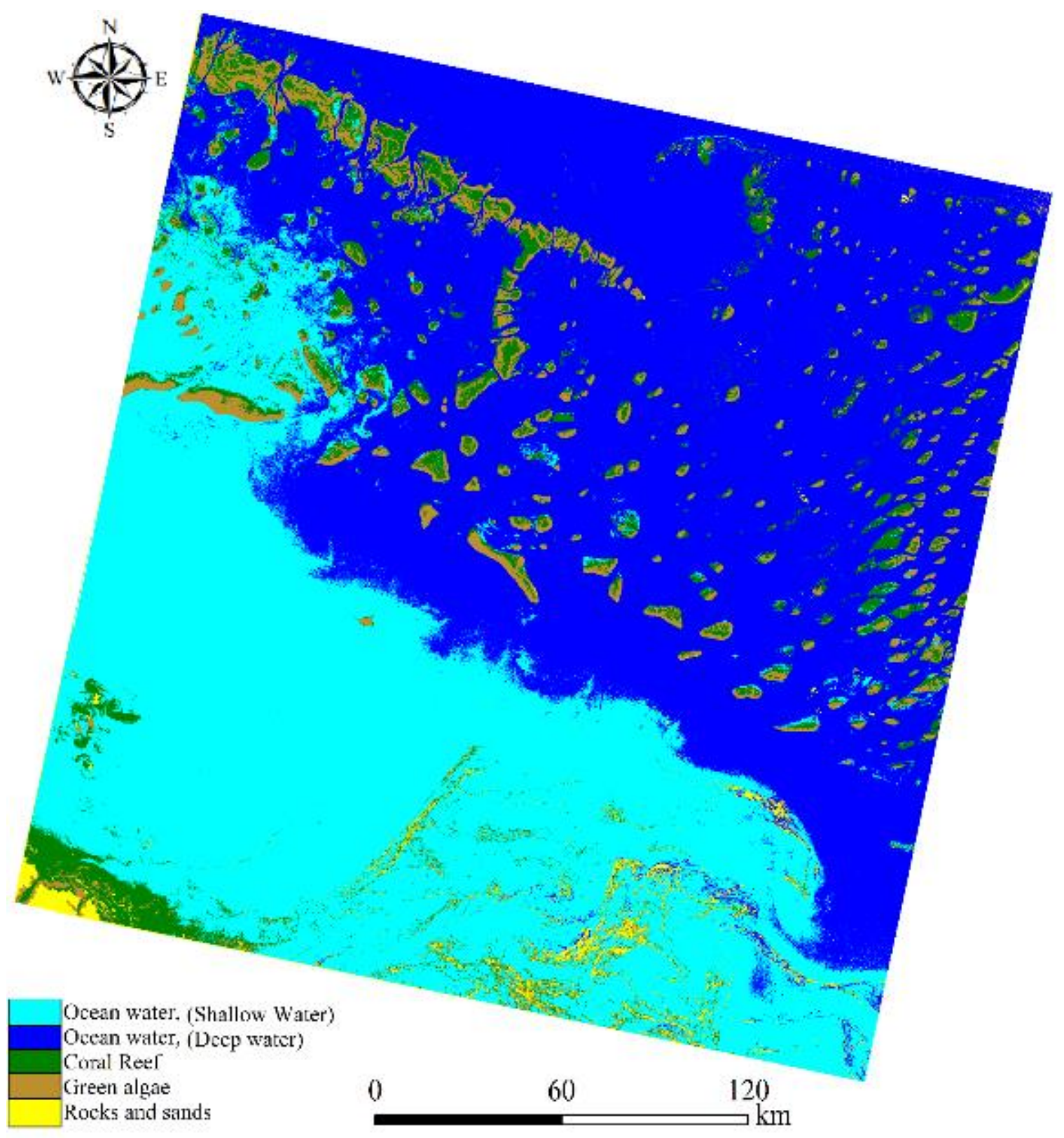

Figure 5 Coral reef map in GBR using Landsat 8 imagery and the Maximum Likelihood algorithm. 

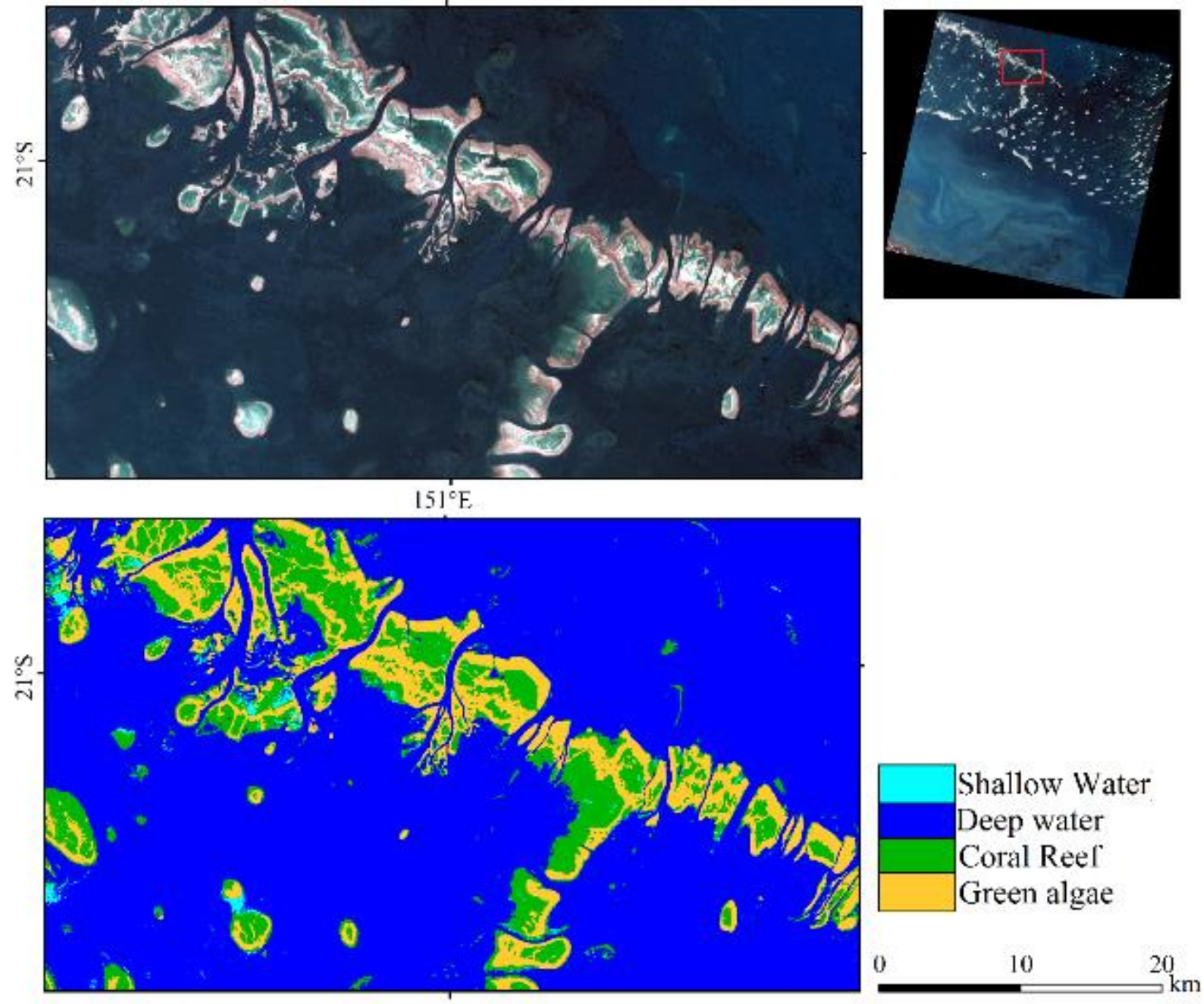

$151^{\circ} \mathrm{E}$

Figure 6 Visual comparison between the (a) classified map and the (b) satellite image of the study area for a zoomed area.

According to Figure 5 and Figure 6, the supervised classification was accurately identified coral reefs along with other classes. This map allows to a better viewing and understanding the characteristics and locations of the coral reefs in GBR. By visual investigating of the produced map, it was also observed that a significant amount of coral bleaching, which is mainly the results of the human impacts, was occurred in some parts of the GBR. Overall, the machine learning algorithm accurately detected coral reefs, which were not visible and distinguishable in the raw Landsat 8 image.

Table 1 shows the confusion matrix of the classification method applied for distinguishing five different classes in the study area. In this confusion matrix, 921 point-based samples, including 231 samples of shallow water, 290 samples of deep water, 137 samples of rocks and sands, 143 samples of green algae and 120 samples of coral reef were considered. 
Table 1 The confusion matrix of the applied classification method

\begin{tabular}{|c|c|c|c|c|c|c|c|}
\hline \multirow{9}{*}{$\begin{array}{c}\text { Ground } \\
\text { truth }\end{array}$} & & \multicolumn{5}{|c|}{ Predicted class } & \\
\hline & & $\begin{array}{c}\text { Shallow } \\
\text { water }\end{array}$ & $\begin{array}{l}\text { Deep } \\
\text { water }\end{array}$ & $\begin{array}{c}\text { Rocks and } \\
\text { sands }\end{array}$ & $\begin{array}{l}\text { Green } \\
\text { algae }\end{array}$ & Coral reef & \\
\hline & Shallow water & 198 & 10 & 1 & 1 & 21 & 0.86 \\
\hline & Deep water & 0 & 283 & 2 & 12 & 3 & 0.94 \\
\hline & Rocks and & & & & & & \\
\hline & sands & 0 & 0 & 124 & 9 & 4 & 0.91 \\
\hline & Green algae & 6 & 0 & 7 & 125 & 5 & 0.87 \\
\hline & Coral reef & 12 & 5 & 0 & 3 & 100 & 0.83 \\
\hline & & 0.92 & 0.945 & 0.93 & 0.83 & 0.75 & 0.90 \\
\hline
\end{tabular}

Based on the results of Table 1, deep water was identified more accurately than other classes. Coral reef could also be distinguished from other classes with the least accuracy. In fact, coral reef was usually confused with shallow water. This issue was understandable from the histograms of these two classes, which are represented in Figure 4. According to Figure 4, in almost all of the bands of Landsat 8, the spectral properties of coral reef and shallow water were similar, and the training samples of these classes had close peaks. In general, the proposed method was able to identify five different classes with an average accuracy of $90 \%$.

Overall, the technique used in this study provided relatively simple and reliable results. It is expected that employing high-quality ancillary data, such as high-resolution aerial photography or bathymetric Lidar products could considerably increase the level of accuracy. Additionally, as mentioned before, due to the absence of in-situ data, training and validation samples were retrieved from satellite image. However, future studies should aim to collect in-situ data to make the model more robust and accurate.

\section{Conclusions}

Coral reefs play an important role in the marine ecosystem and are the habitats for thousands of marine lives. Climate change, industrialization, and anthropogenic disturbance threaten this ecosystem. In this regard, the GBR in Australia is no exception. GBR is the largest coral reef ecosystem in the world. The vitality of the GBR is threatened by multiple factors, such as climate change, industrialization, and anthropogenic activities. Since the majority of the threats identified to be harming the diversity of marine life on the GBR are worsening, timely access to accurate monitoring and mapping the ecosystem of this area is relevant for many applications. The importance of monitoring these ecosystems is rapidly growing due to the continued impacts of pollution and climate change which is threatening coral reefs through coral bleaching. RS techniques along with machine learning algorithms present great promise as a mean of monitoring the coral reefs and detecting accurate classification of characteristics of coral reef ecosystems. By performing a supervised classification and creating a classified map of GBR, the health of coral reef ecosystems and the coral bleaching of the GBR can be also monitored. The 
methods applied to this study allowed for an accurate classification of the GBR. The Maximum Likelihood classification that was performed also allowed for a relatively efficient and accurate supervised classification of bleached coral reefs, coral reefs, submerged reefs, zooxanthellae, and ocean.

\section{Author Contributions}

Erina White and Farzane Mohseni carried out the experiments and wrote the manuscript. Meisam Amani supervised the study and professionally optimized the paper.

\section{Competing Interests}

The authors have declared that no competing interests exist.

\section{References}

1. Spalding $M$, Grenfell A. New estimates of global and regional coral reef areas. Coral reefs. 1997; 16: 225-230.

2. Burke L, Reytar K, Spalding M, Perry A. Reefs at risk revisited. Washington: World Resources Institute; 2011.

3. Beck MW, Losada IJ, Menéndez $P$, Reguero BG, Díaz-Simal $P$, Fernández $F$. The global flood protection savings provided by coral reefs. Nat Commun. 2018; 9: 2186.

4. Spalding M, Burke L, Wood SA, Ashpole J, Hutchison J, Zu Ermgassen P. Mapping the global value and distribution of coral reef tourism. Mar Policy. 2017; 82: 104-113.

5. Obura DO, Appeltans W, Amornthammarong N, Aeby G, Bax N, Bishop J, et al. Coral reef monitoring, reef assessment technologies, and ecosystem-based management. Front Mar Sci. 2019; 6: 580.

6. Abdullah AL, Anscelly AA, Mohamed J, Yasin Z. Conservation of pulau payar marine park and optical remote sensing models. KEMANUSIAAN Asian J Humanit. 2016; 23: 79-107.

7. Stuart-Smith RD, Brown CJ, Ceccarelli DM, Edgar GJ. Ecosystem restructuring along the Great Barrier Reef following mass coral bleaching. Nature. 2018; 560: 92-96.

8. Richards ZT, Day JC. Biodiversity of the Great Barrier Reef-How adequately is it protected? Peer J. 2018; 6: e4747.

9. Wilson SP, Verlis KM. The ugly face of tourism: Marine debris pollution linked to visitation in the southern Great Barrier Reef, Australia. Mar Pollut Bull. 2017; 117: 239-246.

10. Roelfsema CM, Kovacs EM, Ortiz JC, Callaghan DP, Hock K, Mongin M, et al. Habitat maps to enhance monitoring and management of the Great Barrier Reef. Coral Reefs. 2020; 39: 10391054.

11. Amani M, Candace M; Sahel M; Mardi G; Justin S. Aquatic vegetation mapping using machine learning algorithms and bathymetric LiDAR data: A case study from Newfoundland and Labrador, Canada. J Ocean Technol. 2021; 16: 76-94.

12. Nimalan K, Thanikachalam M, Usha T. Estimating the fractional abundance of coral reef benthic compositions using linear spectral unmixing. Int J Fish Aquat Sci. 2020; 8: 181-186.

13. Purkis SJ. Remote sensing tropical coral reefs: The view from above. Ann Rev Mar Sci. 2018; 10: $149-168$. 
14. Hedley JD, Roelfsema CM, Chollett I, Harborne AR, Heron SF, Weeks S, et al. Remote sensing of coral reefs for monitoring and management: A review. Remote Sens. 2016; 8: 118.

15. Kabiri K, Pradhan B, Samimi-Namin K, Moradi M. Detecting coral bleaching, using QuickBird multi-temporal data: A feasibility study at Kish Island, the Persian Gulf. Estuar Coast Shelf Sci. 2013; 117: 273-281.

16. Kabiri K, Rezai H, Moradi M. Mapping of the corals around Hendorabi Island (Persian Gulf), using Worldview-2 standard imagery coupled with field observations. Mar Pollut Bull. 2018; 129: 266-274.

17. Parsons S, Meisam A; Armin M. Ocean colour mapping using remote sensing technology and an unsupervised machine learning algorithm. J Ocean Technol. 2021; 16: 103-115.

18. Roy DP, Wulder MA, Loveland TR, Woodcock CE, Allen RG, Anderson MC, et al. Landsat-8: Science and product vision for terrestrial global change research. Remote Sens Environ. 2014; 145: 154-172.

19. Vanhellemont $Q$, Ruddick K. Advantages of high quality SWIR bands for ocean colour processing: Examples from Landsat-8. Remote Sens Environ. 2015; 161: 89-106.

20. Franz BA, Bailey SW, Kuring N, Werdell PJ. Ocean color measurements with the Operational Land Imager on Landsat-8: Implementation and evaluation in SeaDAS. J Appl Remote Sens. 2015; 9: 096070.

21. Gordon HR, Morel AY. Remote assessment of ocean color for interpretation of satellite visible imagery: A review. Berlin: Springer Science \& Business Media; 2012.

22. Behrenfeld MJ, Boss E, Siegel DA, Shea DM. Carbon-based ocean productivity and phytoplankton physiology from space. Global Biogeochem Cycles. 2005; 19. doi: 10.1029/2004GB002299.

23. Xiong $\mathrm{Y}$, Ran $\mathrm{Y}$, Zhao $\mathrm{S}$, Zhao $\mathrm{H}$, Tian $\mathrm{Q}$. Remotely assessing and monitoring coastal and inland water quality in China: Progress, challenges and outlook. Crit Rev Environ Sci Technol. 2020; 50: 1266-1302.

24. Ilori CO, Pahlevan N, Knudby A. Analyzing performances of different atmospheric correction techniques for Landsat 8: application for coastal remote sensing. Remote Sens. 2019; 11: 469.

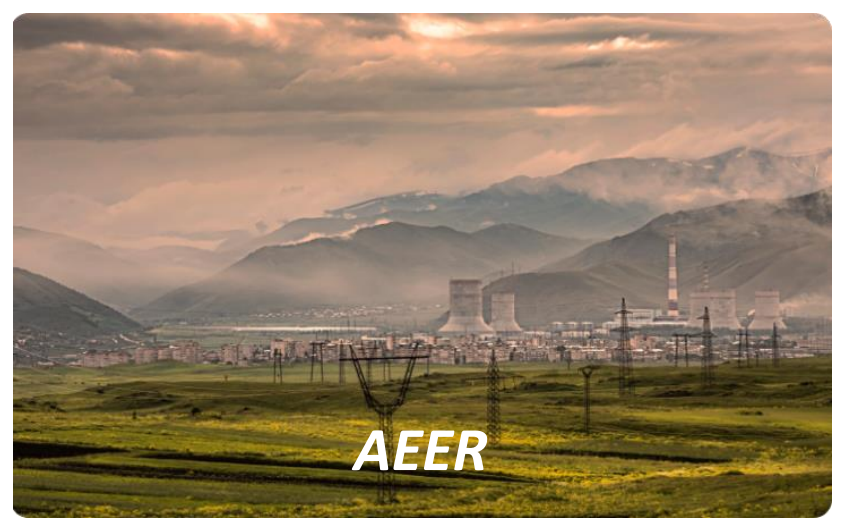

Enjoy AEER by:

1. Submitting a manuscript

2. Joining in volunteer reviewer bank

3. Joining Editorial Board

4. Guest editing a special issue

For more details, please visit: http://www.lidsen.com/journals/aeer 